\title{
A study of the effect of the combined application of a physiotherapeutical program with therapeutic fit balls in cases of chronic pain in the lumbar area.
}

\author{
Petya Kasnakova ${ }^{1}$, Anna Mihaylova ${ }^{1}$, Nikoleta Traykova ${ }^{1,2}$, Penka Petleshkova ${ }^{1^{*}}$ \\ ${ }^{1}$ Medical College, Medical University of Plovdiv, Bulgaria \\ ${ }^{2}$ Department of Radiology, UMHAT St. George Plovdiv, Bulgaria
}

\begin{abstract}
Objective: To investigate the efficiency of the combined application of a physiotherapeutical program with fit-ball exercises in cases of chronic pain in the lumbar area.

Subjects and method: 38 out-patients aged 39 to 67 , with chronic pain in the lumbar area (dating back from 5-7 years, with last exacerbation 5-6 weeks prior to the patients' inclusion in the study), participated in the study. The patients were divided into two groups-a test group in whose physiotherapy program fit-ball exercises were included, and a control group performing standard analytical exercise routines. The pain was reported in the Visual Analogue Scale of Pain Intensity (VASPI). Muscular testing was performed at the beginning and at the end of the physiotherapy program. The physiotherapy rehabilitation program was implemented once a day during the out-patients' procedures in medical centres, and three time a week-at home.

Results and discussion: At the end of the period of monitoring the condition of the patients, changes in the nature of the pain were reported in both groups: with initial levels of VASPI 3.50 for both groups, at the end of the treatment program the level reported by the test group was VASPI 2.00, and VASPI 3.00by the control group. The continuous physiotherapy program including fit-balls leads to an improvement of the movements and a reduction of the dysfunction in cases of chronic pain in the lumbar area of the spine. The exercise programs using fit-balls performed at home enhance the functional capacity of the lumbar spine.
\end{abstract}

Keywords: Exercise balls/fit-balls, Chronic pain in the lumbar area of the spine.

Accepted on January 18, 2019

\section{Introduction}

Pain in the lumbar spine is the most common human suffering. Almost everyone will experience low back pain at some point in their lives. This pain can vary from mild to severe. It can be short-lived or long-lasting. However it happens, low back pain can make many everyday activities difficult to do.

When we stand, the lower back is functioning to support the weight of the upper body. When we bend, extend, or rotate at the waist, the lower back is involved in the movement. Therefore, injury to the structures important for weight bearing, such as the bony spine, muscles, tendons, and ligaments, often can be detected when the body is standing erect or used in various movements.

The lumbar spine, or low back, is a remarkably wellengineered structure of interconnecting bones, joints, nerves, ligaments, and muscles all working together to provide support, strength, and flexibility. However, this complex structure also leaves the low back susceptible to injury and pain [1].
The low back, or lumbar area, serves a number of important functions for the human body. These functions include structural support, movement, and protection of certain body tissues [2].

The treatment very much depends on the precise cause of the low back pain. Moreover, each patient must be individually evaluated and managed in the context of the underlying background health status and activity level.

British researchers found that those who believed that their symptoms had serious consequences on their lives and that they had, or treatments had, little control over their symptoms were more likely to have a poor outcome [2].

Pain can vary from a dull constant ache to a sudden sharp feeling [3]. Low back pain may be classified by duration as acute (pain lasting less than 6 weeks), sub-chronic (6 to 12 weeks), or chronic (more than 12 weeks).

About $40 \%$ of people have LBP at some point in their lives [4], with estimates as high as $80 \%$ among people in the developed world. Men and women are equally affected [1]. Low back pain is more common among people aged $40-80$ years, with the 
overall number of individuals affected expected to increase as the population ages [4].

Low back pain is not a specific disease but rather a complaint that may be caused by a large number of underlying problems of varying levels of seriousness [1]. The majority of LBP does not have a clear cause but is believed to be the result of nonserious muscle or skeletal issues such as sprains or strains. Obesity, smoking, weight gain during pregnancy, stress, poor physical condition, poor posture and poor sleeping position may also contribute to low back pain [1].

\section{Treatment}

In general, treatment for low back pain falls into one of three categories: medications, physical medicine, and surgery.

Physical therapy can include passive modalities such as heat, ice, massage, ultrasound, and electrical stimulation. Active therapy consists of stretching, weight lifting, and cardiovascular exercises. Exercising to restore motion and strength to your lower back can be very helpful in relieving pain.

Chiropractic or manipulation therapy is provided in many different forms. Some patients have relief from low back pain with these treatments.

Traction is often used, but without scientific evidence for effectiveness.

Other exercise-based programs, such as Pilates or yoga are helpful for some patients [5].

Exercise appears to be useful for preventing low back pain [6]. Exercise is also probably effective in preventing recurrences in those with pain that has lasted more than six weeks [7].

Exercise therapy is effective in decreasing pain and improving function for those with chronic low back pain [8]. It also appears to reduce recurrence rates for as long as six months after the completion of program [9]. There is no evidence that one particular type of exercise therapy is more effective than another [10].

There is much controversy on which one is the most appropriate method of treatment and recovery model for chronic low back pain.

There is no perfect physical activity protecting from backache, but there are various suitable exercises that can significantly improve the health status of the patient [11].

Exercises with big fit-balls may prove to be a suitable exercise alternative to the special kinesitherapy exercise programs [12].

This study aims to investigate the effect of the combined application of a physiotherapy program with fit-ball exercises in cases of chronic pain in the lumbar area.

\section{Research Methods}

38 out-patients aged 39 to 67 , with chronic pain in the lumbar area (dating back from 5-7 years, with last exacerbation 5-6 weeks prior to the patients' inclusion in the study), participated in the study. The monitored patients visited physical rehabilitation medical centres in Plovdiv in the period 2017-2018, and were randomly included in the respective groups. According to the type of the pain syndrome, the patients were divided into the following groups: $42.10 \% \pm$ $12.34 \%$ of them were diagnosed with intervertebral disc disease damage; $28.94 \% \pm 13.67 \%$-with low back pain (LBP); $15.79 \% \pm 14.88 \%$-with lumbosacral radiculitis; $13.17 \%$-with lumbar disc herniation (Figure 1). The highest percentage of patients was of those aged 45-55 years, which is indicative of the negative trend towards developing such conditions in working age. It is reported that the affected men $(78.95 \%)$ are two thirds more than the affected women $(21.05 \%)$.

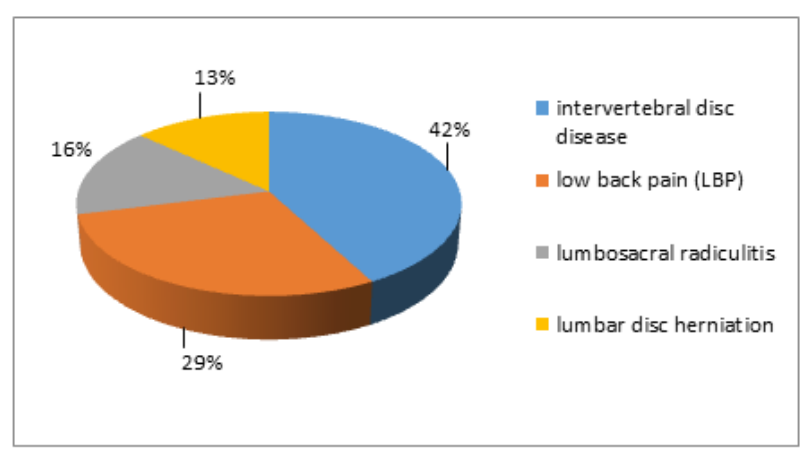

Figure 1. The type of the pain syndrome.

According to the design of the study, the patients were divided into two groups-a test group in whose physiotherapy program fit-ball exercises were included, and a control group performing standard analytical exercise routines. Both groups were also subjected to drug therapy and routine physiotherapy. The monitored patients visited physical rehabilitation medical centres in Plovdiv in the period 2017-2018, and were randomly included in the respective groups.

The test group included 19 patients who performed fit-ball exercises for the body and extremities, for stretching and training muscle groups, and building a strong corset muscle. The fit-balls are mainly used for targeted exercises aimed at strengthening the back muscles, the abdominal muscles, the muscles around the hip joint and the femur surrounding musculature [12]. There is an opportunity for performing the exercises from a relieved position, there is no strain on the big joints, and relaxing, stretching and straining exercises are alternated. The control group consisted of 19 patients who perform standard analytical exercises for the abdominal, gluteal, hip and lumbar musculature, exercises aimed at restoring the muscle balance, at stretching the contacted muscles, and training the patients to perform correctly everyday activities.

The two groups were also administered non-steroid drugs and physiotherapy including low-frequency magnetic field, interference current, ultraphonophoresis, or laser. After the second course of the physical rehabilitation program, the patients included in the study, continued doing the 
recommended exercises at home, following the instructions of their physiotherapist for another two months, three times a week.

All patients declared their informed written consent to be included in the study, and the procedures the patients were subjected to were performed by physical rehabilitation therapists working in the physiotherapy departments at the medical centres.

In order to measure the pain objectively, we used the VASPI method. The standard VASPI scale measures pain, as reported by the patient, from 0 -no pain, to 10 -worst pain ever (unbearable pain).

To determine the functional condition of the lumbar spine, we used the Lumbar disc disease test. The test consists of a dynamic part-test movements measured in centimeters, and a static part-measuring muscle imbalance, remaining in the test position, measured in seconds [13].

\section{Results and Discussion}

The comparative analysis of the groups shows that they are comparable in terms of age and sex. All patients initially reported experiencing pain while walking and performing everyday activities, which an important indicator of the functional condition and quality of life.

The change in the nature and intensity of the pain in both the test and the control groups shows (VASPI: 3,50 at the beginning of the therapy for both groups, VASPI: 3.00 for the test group at the end of the second week, and 3.25-for the control group) the efficiency of the included fit-ball exercisesfor the test group these exercises manifested an analgesic effect for the test group at the end of the second month; this effect lasted during the period and resulted in an improved functional condition. In the control group, the pain persisted throughout the period of the therapy, and the improvement was insignificant (Table 1).

Despite the subjective nature of the reported individual pain, the values of the investigated parameter demonstrated a consistent and permanent trend for an analgesic result from the performed targeted muscular relaxation and balance exercises. Fit-ball exercises improve the balance and coordination of the movements, which indirectly contributes to reducing the risk of exacerbation. The attained results confirm the opinion of a series of authors that muscles are one of the causes of backache and back pain [14-16].

The dynamic part of the muscle test was performed at the beginning of the therapy, after the pain subsided and two months after the start of the therapy. The static part of the test was performed after the pain subsided, and at the end of the physical rehabilitation therapy course [17]. The test is isometric and is discontinued when the body starts trembling or making additional movements. Table 2 shows the results from the dynamic part of the lumbar disc disease test for the test group and for the control one.

The values of the parameters show the range of motion in the lumbar section of the spine in the surveyed groups. Prior to the start of the treatment, both the test and the control groups demonstrated homogeneity as regards the mobility deficit in terms of the parameters-flexion, Schober's test, extension and bending sideways. At the end of the second week, there was a change in the values as compared to the initial ones, more expressed in the test group. At the end of the second month of the therapy, the data in the dynamics show restoration of the functional condition in both groups, but in the test group the low levels of the average norm for healthy people were reached-flexion +3.50 ; extension-35; bending sideways- 18 . Table 3 shows the results from the static part of the lumbar disc disease test for the test group and for the control one.

Table 1. Changes in the average values of pain in the test group and in the control one.

\begin{tabular}{|c|c|c|c|c|}
\hline Index & Groups & $\begin{array}{l}\text { At the beginning of course of } \\
\text { the therapy }\end{array}$ & $\begin{array}{l}\text { The change at the end of } \\
\text { the second week }\end{array}$ & $\begin{array}{l}\text { The change at the end of the } \\
\text { second month }\end{array}$ \\
\hline \multirow{2}{*}{$\begin{array}{l}\text { The pain in the Visual Analogue } \\
\text { Scale of Pain Intensity (VASPI) }\end{array}$} & Test group & 3.50 & 3.00 & 2.00 \\
\hline & Control group & 3.50 & 3.25 & 3.00 \\
\hline
\end{tabular}

Table 2. Dynamic muscle test-the dynamics of the changes in the average values of the parameters of the range of motion in centimeters.

\begin{tabular}{|c|c|c|c|c|}
\hline Tested movement & Groups & $\begin{array}{l}\text { At the beginning of the } \\
\text { therapy }\end{array}$ & $\begin{array}{l}\text { The change at the end } \\
\text { of the second week }\end{array}$ & $\begin{array}{l}\text { The change at the end of } \\
\text { the second month }\end{array}$ \\
\hline & Test group & -5.50 & -2.25 & +3.50 \\
\hline \multirow[t]{2}{*}{ Flexion of the spine forward } & Control group & -6.75 & -3.75 & +3.00 \\
\hline & Test group & 2.00 & 3.00 & 4 \\
\hline \multirow[t]{2}{*}{ Schober's test } & Control group & 2.00 & 2.50 & 3.50 \\
\hline & Test group & 21 & 25 & 35 \\
\hline Extension of the spine & Control group & 19 & 23 & 31 \\
\hline
\end{tabular}




\begin{tabular}{lllll}
\hline \multirow{2}{*}{ Lateral slopes to the left of the spine } & Test group & 13 & 16 & 18 \\
\cline { 2 - 5 } & Control group & 10 & 14 & 17 \\
\hline \multirow{2}{*}{ Lateral slopes to the right of the spine } & Test group & 12 & 15 & 18 \\
\cline { 2 - 5 } & Control group & 12 & 14 & 17 \\
\hline
\end{tabular}

Table 3. Static part of the muscle test in seconds-dynamics of the changes in the average values of the parameters for range of motion.

\begin{tabular}{|c|c|c|c|c|}
\hline Tested movement & Groups & $\begin{array}{l}\text { The beginning of the } \\
\text { therapy }\end{array}$ & $\begin{array}{l}\text { The change at the end of the } \\
\text { second week }\end{array}$ & $\begin{array}{l}\text { The change at the end of the } \\
\text { second month }\end{array}$ \\
\hline & Test group & 18 & 28 & 31 \\
\hline \multirow[t]{2}{*}{ Hip flexors and abdominal muscles } & Control group & 17 & 25 & 27 \\
\hline & Test group & 13 & 30 & 33 \\
\hline \multirow[t]{2}{*}{ For upper back muscles } & Control group & 14 & 24 & 28 \\
\hline & Test group & 23 & 26 & 30 \\
\hline \multirow[t]{2}{*}{ Lower back muscles } & Control group & 11 & 15 & 18 \\
\hline & Test group & 21 & 29 & 31 \\
\hline m. quadratus lumborum & Control group & 18 & 22 & 25 \\
\hline
\end{tabular}

The values of the parameters of the strength of the lumbar and abdominal muscles at the beginning of the course of therapy for both groups do not show a significant difference, whereas after the second week of the therapy there is an increase in the isometric endurance, more expressed in the test group. The values of the parameters after the second month of the therapy in home conditions, as compared to the initial values, are higher in the test group for torso and abdominal muscles flexion-31 seconds, for upper back muscles-33 seconds, for lower back muscles-30 seconds, and for $\mathrm{m}$. quadratus lumborum-31 seconds. For the surveyed period, the changes in the values of the control group show persistence of a certain muscular weakness of the tested muscles.

The information on the clinical improvement obtained through the applied assessment methods gives us grounds to believe that the applied therapy with fit-ball exercises optimizes the quality of life of the surveyed patients.

The positive results from the fit-ball exercises for patients in the test group can be accounted for by the specific effects of the said exercises. The symptoms of the patients were beneficially influenced during the course of the physical rehabilitation therapy, and the positive results remained steady until the end of the second month of the study.

\section{Conclusion}

The good practice of influence using fit-ball exercises, their easy and safe application and the achieved positive results, serve as grounds for recommending various fit-ball exercises, consistent with the functional status of the patient, as part of the comprehensive physiotherapy program for alleviating pain in the lumbar section of the spine. Exercise balls can be included in the physiotherapy exercise programs for prophylaxis and treatment performed at home, provided the patient is first instructed how to do the respective exercises correctly.

In this study we have shared our first experiences of using fitball exercises as a means of influence, as part of a complex physiotherapy program for patients with chronic pain in the lumbar spine. Further research is needed for the purpose of standardizing therapeutic fit-ball exercises and developing various sets of exercises to be performed in the home.

\section{References}

1. National Institute of Neurological Disorders and Stroke. Pain: hope through research. https: //www.ninds.nih.gov/ Disorders/Patient-Caregiver-Education/Hope-ThroughResearch/Pain-Hope-Through-Research 2017.

2. William CS. Low back pain. https: // www.medicinenet.com/low_back_pain/article.htm

3. Koes BW, van Tulder M, Lin CW, Macedo LG, McAuley J, Maher C. An updated overview of clinical guidelines for the management of non-specific low back pain in primary care. Eur Spine J 2010; 19: 2075-2094.

4. Hoy D, Bain C, Williams G, March L, Brooks P, Blyth F, Woolf A, Vos T, Buchbinder R. A systematic review of the global prevalence of low back pain. Arthritis Rheum 2012; 64: 2028-2037.

5. https: //orthoinfo.aaos.org/en/diseases--conditions/lowback-pain/

6. Steffens D, Maher CG, Pereira LS, Stevens ML, Oliveira VC, Chapple M, Teixeira-Salmela LF, Hancock MJ. Prevention of low back pain. JAMA Int Med 2016; 176: 199-208. 


\section{chronic pain in the lumbar area}

7. Choi BK, Verbeek JH, Tam WW, Jiang JY. Exercises for prevention of recurrences of low-back pain. Cochrane Database Syst Rev 2010; 006555.

8. Guild DG. Mechanical therapy for low back pain. Prim Care 2012; 39: 511-516.

9. Smith C, Grimmer-Somers K. The treatment effect of exercise programmes for chronic low back pain. J Eval Clin Pract 2010; 16: 484-491.

10. van Middelkoop M, Rubinstein SM, Verhagen AP, Ostelo RW, Koes BW, van Tulder MW. Exercise therapy for chronic nonspecific low-back pain. Best Pract Res Clin Rheumatol 2010; 24: 193-204.

11. Pengel LH, Refshauge KM, Maher CG, Nicholas MK, Herbert RD, McNair P. Physiotherapist-directed exercise, advice, or both for subacute low back pain: a randomized trial. Ann Intern Med 2007; 146: 787-796.

12. Gencheva N. Fit-ball et kinesitherapie. Bolit Ins 2003.

13. Lianu E. Program for relapsing low back pain prevention consisting of exercises with swiss ball for patients with lumbar disc disease. Kinesitherapie Rehab Physiother Rehab2004; 4: 6-8.
14. Jelev V, Voyadzis H, Lianu E. Amended test for lumbar disc disease. Kinesitherapie Rehab Physiother Rehab 2004; 2: 18-20.

15. Parnianpour M, Wang JL, Shirazi-Adl A, Sparto P, Wilke HJ. The effect of variations in trunk models in predicting muscle strength and spinal loads. J Musculoskelet Res 1997; 1: 55-69.

16. Manniche C, Hesselsoe G, Bentzen L, Christensen I, Lundberg E. Clinical trial of intensive muscle training for chronic low back pain. Lancet 1988; 2: 1473-1476.

17. Manniche C. Clinical benefit of intensive dynamic exercises for low back pain. Scandinavian J Med Sci Sports 1996; 82-87.

\section{*Correspondence to}

Penka Petleshkova

Medical College

Medical University of Plovdiv

Bulgaria 